\title{
NARRATIVA LITERÁRIA E HISTÓRIA: UM OLHAR INTERDISCIPLINAR SOBRE O CONTO O REBELDE, DE INGLÊS DE SOUSA
}

\author{
LITERARY NARRATIVE AND HISTORY: AN INTERDISCIPLINARY \\ LOOK AT THE TALE O REBELDE, BY INGLES DE SOUSA
}

\author{
NARRATIVA LITERARIA E HISTORIA: UNA MIRADA INTERDISCIPLINARIA \\ AL CUENTO EL REBELDE, DE INGLÉS DE SOUSA
}

Laura Neila Costa da Silva[i]

\section{RESUMO}

Este artigo é resultado de uma análise interdisciplinar do conto O Rebelde (1893), do escritor Inglês de Sousa, inserido na estética Realista/Naturalista da literatura brasileira. O conto faz referência ao movimento revolucionário, político e social de Belém do Pará, ocorrido no período de 1835 e 1840, chamado "Cabanagem" partindo de um olhar da Literatura, como forma de expressão artística da sociedade possuidora de historicidade e como fonte documental para a produção do conhecimento histórico. Parte do princípio de que todo texto é representação de realidades, com regras próprias de produção, como observamos em Chartier (1990). E o objetivo é demonstrar possíveis relações entre representações históricas do movimento cabano e representações literárias, através do conto de Inglês de Sousa. Como aporte teórico foram utilizados os historiadores Rocque (1984), Ricci (2001), Lima (1986) e teóricos da área de Teoria Literária Nunes (2003), Eagleton (2006), Zola (1982).

\section{Palavras-chave:}

História social; Literatura; Cabanagem; Literatura naturalista.

\section{ABSTRACT}

This article is the result of an interdisciplinary analysis of the short story O Rebelde (1893), written by Inglês de Sousa, a reference in Realist/Naturalist aesthetics of Brazilian literature. The story refers to the revolutionary, political and social movement in Belém do Pará city, which took place from 1835 to 1840, called "Cabanagem". The story brings the perspective of Literature, as a form of artistic expression for the society with historicity and as a documentary source for the production of historical knowledge. It assumes that every text is a representation of realities, with its own rules of production, as noted in CHARTIER (1990). The study aims to demonstrate a possible connection between historical representations of the cabano movement and literary representations, through Inglês de Sousa's short story. As a theoretical contribution, we based this research on Rocque (1984), Ricci (2001), Lima (1986), Nunes (2003), Eagleton (1997) and Zola (1982).

\section{Keywords:}

Social history; Literature Cabanagem; Naturalistic Literature.

\section{RESUMEN}

Este artículo es el resultado de un análisis interdisciplinar del cuento O Rebelde (1893), del escritor Inglés de Sousa, insertado en la estética realista / naturalista de la literatura brasileña. La historia se refiere al movimiento revolucionario, político y social en la ciudad de Belém del Pará, que tuvo lugar en el período comprendido entre 1835 y 1840, Ilamado "Cabanagem", desde la perspectiva de la literatura, como una forma de expresión artística para la sociedad con historicidad y como fuente documental para la producción de conocimiento histórico. Se supone que cada texto es una representación de realidades, con sus propias reglas de producción, como señala Chartier (1990). El objetivo es demostrar las posibles relaciones entre las representaciones históricas del movimiento cabano y las representaciones literarias, a través del cuento de Inglés de Sousa. Como contribución teórica, se utilizaron los historiadores Rocque (1984), Ricci (2001), Lima (1986) y teóricos del área de la teoría literaria Nunes (2003), Eagleton (1997) y Zola (1982).

\section{Palabras clave:}

Historia social; Literatura; Cabanagem; Literatura naturalista. 


\section{INTRODUÇÃO}

A análise de textos literários é sempre um desafio para o leitor atento, com o mínimo de conhecimento da arte literária, isso porque são construções tão complexas, quanto a seleção temática e metodológica imaginativa que um autor deve realizar para conduzir uma escrita carregada de expressividade. Em meio aos seus pensamentos, seus recortes memorialísticos, sua vida cotidiana, seus posicionamentos ideológicos, suas visões de mundo e as visões de mundo que se apropria, ou seja, a constituição do seu pensamento.

É claro que um autor pode transfigurar literalmente o real ou construir o irreal, sem limitações. Porém, a própria construção daquilo que não o constitui historicamente pode ser uma pista do que sua escrita revela. O grande primeiro passo é buscar sua obra e sua história estética e biográfica, para atravessar caminhos em seu enredo literário e passar a conhecer parte do que o constitui. Neste sentido, os diálogos, a vivência, o contexto histórico, as refutações e o espaço geográfico que está inserido, tornam-se elementos imperativos na construção ficcional do real.

Este trabalho lança um olhar sobre o conto $O$ Rebelde, de Inglês de Sousa, estabelecendo a relação presente entre a construção literária e os reportes históricos, que memorizam o momento histórico, o movimento da Cabanagem. Na primeira parte é analisada a questão de denominação do que seja Literatura na
Contemporaneidade, o texto é apoiado nas análises e afirmações de Terry Eagleton, através da obra Teoria da Literatura: uma introdução (2006)

$\mathrm{Na}$ segunda, dialoga-se com a relação entre Literatura e História, portanto uma leitura 'interdisciplinar', Isso tudo com o intuito de comprender o que revela a história e o que representa do texto literário. A intesdisciplinaridade significa esse diálogo entre as disciplinas em forma de troca teórica e metodológica para novos modos de pesquisa com o texto, na contemporaneidade a "interdisciplinaridade" aparece diante da "disciplinaridade", tal como afirmam Delizoicov e Zanetic (2001, p13): "Ao invés do professor [pesquisador] polivalente,

interdisciplinaridade pressupõe a colaboração integrada de diferentes especialistas que trazem a sua contribuição para a análise de determinado tema.".

Portanto, compreendemos que interdisciplinaridade se caracteriza pela atividade de trocas entre os especialistas e pelo grau de integração das disciplinas no interior de um projeto específico de pesquisa, onde a interdisciplinaridade aparece como um novo modo de reorganização das disciplinas científicas e suas reformulações metodológicas e conceituais, o que se configura em um desafio.

Esta análise se apoia na articulação dessa prática desafiadora entre Teoria Literária e História, no âmbito de análise de construção de textos históricos e textos literiários, com suas escolhas metodológicas e seleções discursivas. Na terceira parte, através de um panorama da história que serve como fundo para o conto de Inglês de Sousa, a Cabanagem, traduzidos pela historiadora brasileira Magda Ricci. A análise se baseia em referências históricas que a autora realizou através de seu artigo intitulado Do sentido aos significados da Cabanagem: percursos historiográfico, publicado no ano de 2001, onde demonstra os principais autores que descrevem a Cabanagem ao longo da história, até o século $X X$ e XXI. Seguidamente há uma breve apresentação sobre o autor e, então, a análise de seu conto, estabelecendo diálogos sobre leituras sobre o Movimento da Cabanagem sob o ponto de vistas dos historiadores.

\section{LITERATURA PARA QUÊ? TEMOS UMA DEFINIÇÃO PARA "LITERATURA"?}

O estudioso e pensador de teorias e paradigmas envolvendo a Literatura (com trabalhos nas áreas de Cultura e História, também), Eagleton (2006), em sua obra Teoria da Literatura: uma introdução realiza um percurso histórico entre literatos ingleses e franceses do século XVII, para demonstrar que a conceituação de "escrita imaginativa" relacionada à literatura, não se encaixa em um todo de análise sobre as obras. Realiza um recorte da história do estudo da literatura até a contemporaneidade,

denominando correntes teóricas cardinais de nosso século. Resumidamente, o autor pretende demonstrar um pouco das concepções para a "moderna teoria literária". 
Descrever o que é literatura nunca foi fácil para nenhum teórico que conhece os mecanismos da linguagem, e tudo que a envolve interna e externamente. O autor aborda de forma direta afirmativas e exemplificações teóricas que dialogam com o sentido de Literatura e o porquê de dadas obras serem denominadas literaturas e outras não, a partir da história literária.

No século XVIII, a Literatura era considerada como todo o conjunto de obras que a sociedade valorizava, e o que classificava uma obra em literária ou não era a "ideologia da classe dominante", segundo o autor. E os primeiros conceitos de literatura surgiram no movimento europeu chamado Romantismo, em um período histórico demarcado pelo crescimento de indústrias, substituições de mão-de-obra e crescimento de sesigualdades sociais. Para os românticos, a literatura era uma forma de evasão e simbolizava sua ideologia, de forma camuflada e sua contestação à ideologia e política impostas. Chega um momento em que os românticos passam a ser privados de toda e qualquer adequação aos movimentos sociais que acompanham sua produtividade, o que gera o surgimento de uma fase solitária de produção, a arte passa a ser isolada das relações sociais e, nesse mesmo período surge 0 campo da Filosofia da Arte expandindo a concepção geral.

Eagleton (2006, p.120) salienta que "a literatura não pode ser produto do isolamento, tendo em vista que ela nasce do sujeito coletivo". Ao longo do século XIX, O imperialismo inglês, com $O$ crescimento substancial de sua produção industrial, vislumbrou a necessidade da existência de um veículo que disseminasse valores e práticas burguesas para as classes minoritárias trabalhadoras, ou seja, as operárias. Este papel coube a literatura.

No quarto capítulo de sua obra, o autor expõe o surgimento do 'pós-estruturalismo' como autocrítica ao 'estruturalismo3 ', alegando que é limitado por não relacionar a obra em questão, com a realidade na qual está inserida, e também para qual está sendo produzida, acabando por instaurar uma teoria da desconstrução da análise literária e sujeitando o texto a uma pluralidade de sentidos. Essa desconstrução seria entendida como "uma passagem da obra para o texto", onde não há nada que já não tenha sido escrito, tudo surge de uma intertextualidade ou é reescrito. Como afirma, Eagleton (2006):

Seria ilusão pensar que poderia estar plenamente presente ao leitor aquilo que digo ou escrevo, porque o uso dos signos sempre implica alguma dispersão das minhas significações, implica sua divisão, e o fato de que jamais serão idênticas a si mesmas em todas as ocasiões. (EAGLETON, 2006, p.179).

Os pós-estruturalistas compreendem a instabilidade da linguagem escrita e determinam teoricamente que linguagem não deve ser concebida como um "sistema estável e muito bem delimitado", devido todos os elementos serem interligados Passando a privilegiar o uso da fala em prejuízo à escrita, tendo em vista que através desta a impessoalidade toma conta do discurso e pode deturpar a mensagem, enquanto que aquela transmite o discurso de maneira íntima e espontânea. É neste movimento científico que a crítica literária passa a ver a literatura como elemento capaz de formar a consciência crítica do leitor sobre a realidade do mundo. É quando a literatura ganha caráter popular, sendo inseridos personagens de classes marginalizadas e suas mazelas, como figura de negros, mulheres, pobres e mesmo homossexuais.

Eagleton (2006, p.180) Derrida[1] foi o propagador dessa corrente teórica, foi utilizando da chamada crítica desconstrutiva para demonstrar "como um texto pode embaraçar seus próprios sistemas lógicos dominantes". Seus princípios desconstrutivistas disseminados não alcançaram o objetivo, o que encarregou a crítica literária pós-estruturalista da garantia sobrevivência desses pensamentos idealistas.

Pensando em Literatura como objeto artístico ligado diretamente à prática social e a construção de ideologias, visualizamos um texto que produzido por uma perspectiva histórica, social e cultural propõe pensar este real, portanto a ficcionalidade está ligada à uma proposta de olhar, de uma cultura, de uma história.

\section{LITERATURA E HISTÓRIA: INTERFACES ENTRE O REAL E NARRATIVO}

A grande conclusão de Eagleton (2006), através de sua obra Teoria Literária, é de que não há 
motivos consistentes para se debater a hipótese de a Literatura estar relacionada ou não com a história; indica uma releitura dessa própria história. Trata-se de utilização de estratégia para analisar os efeitos ideológicos produzidos por determinados significantes de um texto literário:

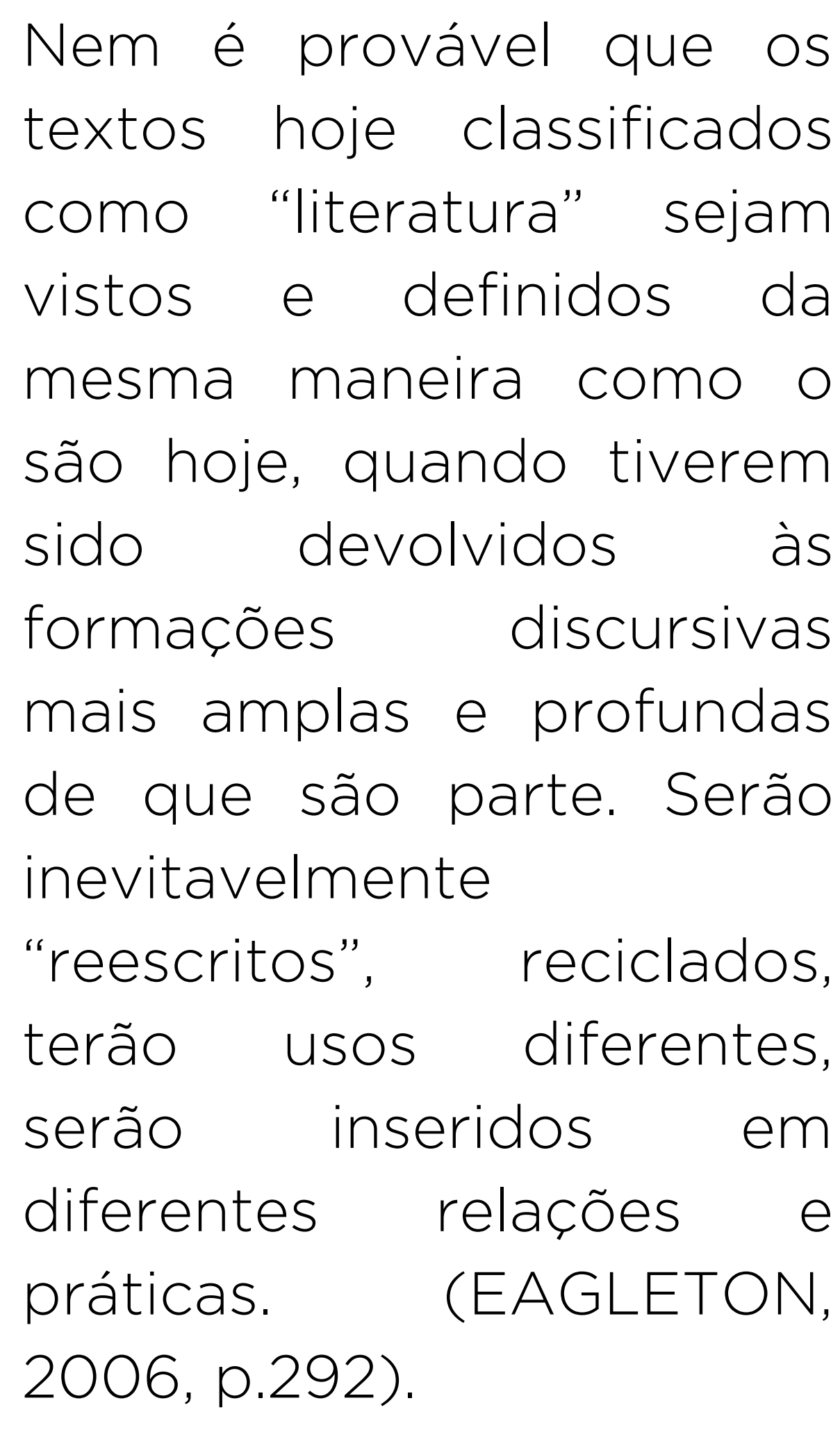

O autor cita o Homero lido na contemporaneidade, não é igual ao Homero da Idade Média, nem o 'nosso Shakespeare' é igual ao dos contemporâneos desse autor. As obras acabam sendo reescritas de acordo com a sociedade que as leem, mesmo que de forma inconsciente. 0 que demonstra como classificar a Literatura se torna "instável". Portanto, a Literatura ao longo da história parece ser compreendida de acordo como dado grupo determina que seja compreendida.

com legitimidade e credibilidade social para demarcar sua ideologia e crítica referente de domínio literário, ou de forma sintetizada à luz de interesses próprios realizamos leituras com dados significados, munidos de nossas referencias contextuais. Até os dias de hoje, em debates que envolvem Literatura e História, por exemplo, alguns textos são denominados por historiadores como sendo documento histórico, e pelos

profissionais de Letras como Literatura, ou seja, texto carregado de uma escrita imaginativa, carregada com figuras de linguagens expressivas, construções linguísticas mais elaboradas do ponto de vista formal, com teor ficcional, etc., como as cartas de cronistas na época das Grandes Navegações, na história dos "achamentos" das terras brasileiras.

pensamento de Chartier (1990), legitima o texto literário como reconstrutor do real.

\begin{abstract}
Todo documento, seja ele literário ou de qualquer outro tipo, é representação do real que se apreende e não se pode desligar de sua realidade de texto construído pautado em regras próprias de produção inerentes a cada gênero de escrita, de testemunho que cria "um real" na própria "historicidade de sua produção e na intencionalidade da sua escrita" (CHARTIER, 1990, p. 62-3)
\end{abstract}

Muitos discursos são formados para defender o que seja ou não um texto literário, músicas de cânticos populares transmitidos pela oralidade, por exemplo não são consideradas literatura, para a crítica literária vigente, porém as músicas do artista brasileiro Chico Buarque de Holanda o são, por alguns críticos, por serem escritas com um vigor linguístico e riqueza narrativa, porém a riqueza narrativa dos cânticos populares está no contexto a que são inseridas. Não seriam uma construção textual tão complexa, criativa e

importante quanto as de Chico? Aqui mora o discurso de literatura como "a bela escrita”, ou a escrita rebuscada, aperfeiçoada, longe da linguagem comum. O mesmo discurso que paira na academia sobre os chamados livros de "autoajuda".

O mais importante certamente é "dialogar", equiparar discursos avessos e afins, analisar o percurso de construção histórica, social, ideológica e artística de um autor e suas tendências, além de pontos de vista sobre sua obra. O verossímil que sofre oscilações...

Uma forma de compreendermos literatura é analisar sua relação com domínios da história, visto que o texto literário é uma construção de palavra emoldurada de acordo com concepções de um indivíduo constituído socialmente, mesmo que este tenha relação de contato social restrito Analisando o fundo social, cultural, a memória representada e posicionamentos ideológicos, construídos muitas vezes em suas entrelinhas. Este jogo de pensamento entre o real e o ficcional em suas óticas adversas e próximas, ao mesmo tempo, quando se trata de literatura, nos remete a conceituações pragmáticas para a interpretação do texto literário.

\section{A LITERATURA QUE MOSTRA A HISTÓRIA E A HISTÓRIA QUE SE UTILIZA DA LITERATURA: ANÁLISE DO CONTO O REBELDE DE INGLÊS DE SOUSA.}

Na contemporaneidade a história que se detinha em mostrar os "acontecimentos" reais, hoje busca as várias perspectivas para uma possivel realidade - ou ainda possíveis realidades - e o campo de estudos literários cada vez mais 
reconhece que a literatura, mesmo que construção de apelo artístico é uma perspectiva real também. E os estudos amadurecem cada vez mais, como observamos em Lima (1986), sobre o discurso literário:

O discurso literário não se apresenta como prova, documento, testemunho do que houve, portanto o que nele está se mescla com o que poderia ter havido; o que nele há se combina com o desejo do que estivesse; e que por isso passa a haver e estar". Nesta perspectiva é "o que poderia ter havido", ou seja, uma criação do possível real, construída pelo olhar através do real. (LIMA, 1986, p.195)

Analisar um texto narrativo literário faz do profissional dedicado ser, também, um investigador de pistas históricas, memorialísticas e culturais. Dito que cada autor possui uma história e um conjunto de memórias que o constitui como ser pensante e, por trabalhar com a matéria artística. emoldura a realidade de acordo com suas visões ou seu modo de demonstrar pontos de vista.

O contista Inglês de Sousa, demonstram temáticas envoltas de choques políticos, econômicos e sociais que contam a história dos indivíduos marginalizados historicamente, no interior da Amazônia. E dentre as narrativas encontramos movimentos sociais marcantes na história brasileira, dentre eles a Guerra do Paraguai e a Cabanagem, a segunda narrada nos contos A quadrilha de Jacó Patachó e 0 Rebelde. Apesar de escritos no final do século XIX, as obras têm como pano de fundo tempos históricos que atravessam todo o século, referenciando momentos importantes de seu processo sociopolítico.

\section{O MOVIMENTO DA CABANAGEM E A HISTÓRIA}

Segundo a historiadora Magda Ricci (2001), no século XIX, atritos nas forças militares, aumento dos impostos para sustento dos gastos da Coroa Portuguesa instalada no Rio de Janeiro, que só podia contar então com a Colônia, e um forte crescimento das desigualdades regionais formam um contexto propício a manifestações e revoltas populares no Rio de Janeiro e demais colônias brasileiras.

E, em Março de 1817, acontece em Pernambuco a primeira manifestação, quando grande parte da população pernambucana, composta de proprietários rurais, artesãos, comerciantes, juízes, militares e até sacerdotes, inicia uma revolta, começando por Recife e se estendendo para o sertão. Tudo devido à insatisfação com um desfavorecimento regional (já que o deslocamento da Coroa para o Rio de Janeiro parecia privilegiar apenas o espaço do próprio Rio, ignorando o nordeste, como acreditavam) e o descontentamento com os benefícios concedidos aos portugueses imigrados no Nordeste. Respectivamente, duas espécies de "patriotismo", relativas àqueles sentimentos, orientavam a mentalidade da revolta: uma, localizada, referente ao nordeste e sua independência em relação ao resto do Brasil; outra, mais genérica, calcada em um antilusitanismo e na afirmação da legitimidade dos brasileiros contra os portugueses.
Os revolucionários tomam Recife e declaram sua independência, porém, dois meses após o início da revolta, são vencidos pelas tropas portuguesas, em função de sua desorganização e, para além daqueles sentimentos comuns, da variação de seus ideais, que iam do idealismo mais apaixonado aos interesses de ordem estritamente econômica.

Segundo Ricci, em Do Sentido aos Significados da Cabanagem: percursos historiográficos (2001), pertencente aos Anais do Arquivo Público do Pará, a Cabanagem simboliza "um movimento social conhecido por um conjunto de explicações históricas elaboradas nos últimos 163 anos", O qual aconteceu entre 1835 e 1836. A possível datação é de 7 de janeiro de 1835, quando a cidade de Belém é invadida por rebeldes, os quais mataram o presidente da Província e autoridades, tomando o poder da cidade. Estes foram conhecidos como "cabanos", caracterizados em grande parte como homens do povo que, por "opressões das autoridades regenciais" e "o despotismo das elites do Pará", rebelam-se contra o poder imperial.

Segundo a autora, o primeiro historiador a falar sobre o movimento, ou melhor, sobre os movimentos políticos do Brasi Regencial, no século XIX, foi Domingos Raiol, quem caracterizou a Cabanagem como movimento político e marcado pela anarquia, denominando-a " o último e maior motim, o mais funesto e o de maiores consequências" (RICCl, 2001, p.246).

Como observamos no artigo, o Barão de Guajará (denominação 
dada a Raiol) os cabanos simbolizaram o vandalismo, a anarquia social, que acaba se estabelecendo na cidade pelo descaso determinante das autoridades instaladas advindas de Portugal. Para Raiol tudo começa no Rio de Janeiro, quando se forma uma "ação facciosa" de alguns homens politizados, os quais chama de "homens atrabiliários" que começam a realizar uma incitação das massas incultas a promoção de motins. E com a abdicação de Pedro I, em 7 de Abril de 1831, a anarquia começa a ser estabelecida, ocasionando várias mortes, pelo fato de não haver autoridades vigentes. E no Pará o fato se repete em 7 de Agosto de 1831.

Em 1930 surgem novas considerações e trabalhos sobre a Cabanagem, como os de Henrique Hurley e Dilke de Barbosa Rodrigues e Ernesto Cruz, os quais junto ao Instituto Histórico e Geográfico do Pará, começam a debater memória histórica do Pará, do século XIX. E afirmam que a Cabanagem teve um antecedente histórico importante, o "brigue palhaço" em Belém, marcado pelo massacre de prisioneiros, simbolizando um fato marcante para adesão do Pará à Independência.

Ricci (2001) descreve que Hurley compreende a Cabanagem como um "movimento social" demarcado pela opressão de portugueses sobre os nativos indígenas, determinados em seu primeiro livro "A Cabanagem". Neste trabalho o cabano passa a ser visto como parte da hierarquia social, passa a ser objeto de estudo, sem negar a importância das lideranças imperiais. Dilke apud Ricci
(2001), por sua vez, detém-se a estudar os lideres cabanos, dentre eles, Eduardo Nogueira Angelim, que passa a ser colocado como herói e não como rebelde, afirmando que este só não foi um herói nacional por ter ido de encontra com a luta pela "formação e unidade nacional". Ernesto Cruz[2], procurando detalhes do movimento e dos escritos sobre a Cabanagem, complementa o trabalho alegando que os cabanos almejavam também uma unidade nacional. Estas produções se posicionavam na tentativa de compreender a constituição do caboclo amazônico. Percebe-se que os trabalhos passam a legitimar a posição dos líderes cabanos diante do governo regencial e a problematização da formação de nacionalidade de instala.

Nos anos 80 os estudos sobre a Cabanagem são aprimorados e Carlos Rocque, Júlio José Chiavenato, Pasquale Di Paolo e Vicente Salles surgem com novos trabalhos. Rocque era um

jornalista, também ligado ao Governo do Estado do Pará. "Lutava pelo 7 de Janeiro e pela eleição dos ideais cabanos enquanto ideais libertários do povo paraense"(SARGES; $\mathrm{RICCl}$ 2013, p.254), fol responsável pela inauguração e diretoria de um museu em memória a cabanagem, o Memorial da Cabanagem, idealizado por Niemayer, que simbolizou a quebra temporal da derrota dos

cabanos em 1836. O interesse do autor foi trazer a memória os líderes cabanos, tornandoos de forma concreta heróis.

Chiavenato, citado no texto de
Ricci (2001) publicou livros descrevendo a Cabanagem como um símbolo de ação revolucionária da "massa cabana”, a revolução popular, como forma de exemplo para o Brasil e a América Latina:

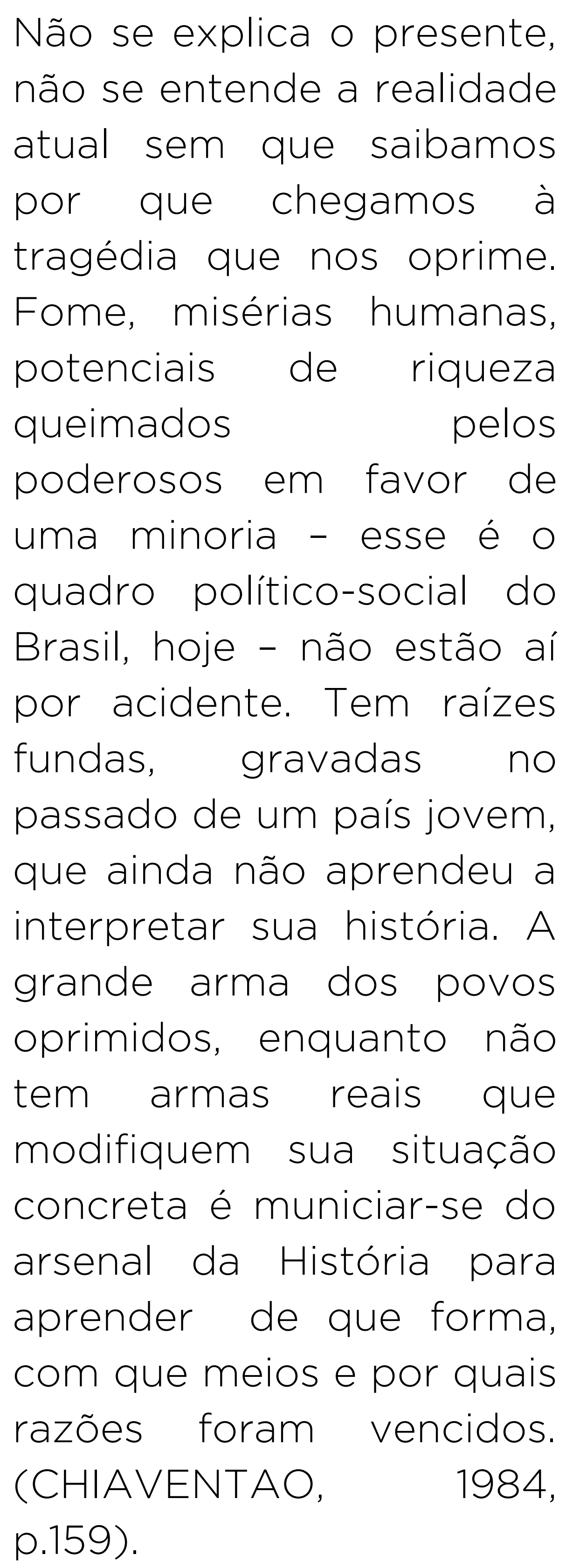

Para Rocque (1984) temos Angelim e Batista Campos como líderes glorificados em oposição ao General Andréa, dentre outros, comparados aos nazistas. E para Chiavenato temos os cabanos como "heróis sem rosto", presentes na massa popular, quem vão de encontro com os contrarrevolucionários. O que tem como concordância é que a luta dos cabanos fo ligada aos instintos e com a falta de consciência política destes e da massa populacional, não teria forças para imperar por muito tempo.

O sociólogo Di Paolo, segundo Ricci (2001), recorre a outra ótica a respeito dos cabanos, o momento da cabanagem se situou entre lutas 
colônia/metrópole, quando o país deixa de ser o "centro comercial metropolitano e passa a ser intermediário internacional da borracha". E afirma em seus estudos que:

Da análise geo-histórica da Amazônia emerge não só a centralidade sócio-política de Belém, mas também sua mediação absolutista, imposta pelos grupos dominantes para explorar as riquezas regionais. (...) O momento mais alto da luta pela igualdade e pela liberdade na Amazônia é, sem dúvida alguma, o movimento cabano: de fato a cabanagem constitui o movimento revolucionário popular mais autêntico e significativo de toda a história. ( $\mathrm{RICCl}, 2001$ p.32).

Alguns anos atrás das narrativas históricas, em Rocque (1984), a historiadora ítala Bezerra da Silveira, pesquisando no arquivo nacional da cidade do Rio de Janeiro, e um quantitativo de presos cabanos registrados, conseguiu chegar ao percentual de $50 \%$ de brancos, declarando que mesmo assim o quantitativo de índios é maior, visto que a população era em sua maioria indígena, porém estes tinham mais facilidades nas fugas pelos rios e matas.

Percebe-se que cada historiador consegue identificar algo novo no movimento, ao longo das décadas e isso não para. E a autora do artigo que faz esse panorama de visões da história da Cabanagem, Ricci (2001) afirma que é apenas o começo, que muitas histórias individuais estão esperando para serem descobertas e a "Grande quantidade de escravos, senhores e homens livres podres que, experimentaram as mais diferentes e contraditórias expectativas e lutas dentro do mesmo movimento cabano" (RICCl, 2001, p.271), e ficam "em aberto" os questionamentos de como um movimento teve tantas pessoas envolvidas, criando uma "memória tão marcante e diversificada no Pará" palavras de Magda.

\section{O MOVIMENTO DA \\ CABANAGEM E A LITERATURA}

Através do prefácio da obra Contos Amazônicos (2005), conhecemos um pouco sobre Herculano Marcos Inglês de Sousa. Ele nasceu em Óbidos, no Pará, em 28 de Dezembro de 1853. Seu pai foi o desembargador Antônio Rodrigues de Sousa e sua mão D. Henriqueta Amália de Góis Brito Inglês, pertencentes às famílias mais tradicionais paraenses. Aos 11 anos mudou para o Maranhão para estudar no Colégio de Sotero dos Reis. Aos 14 anos foi internado no Colégio Perseverança, no Rio de Janeiro, para realizar o ensino secundário. Nesta época escreveu uma obra completa com drama, romance e poesias líricas e heroicas, a qual o diretor confiscou. Após o ensino preparatório, ingressou na faculdade de Direito de São Paulo, aos 17 anos.

No quarto ano de faculdade escreveu a primeira obra $\mathrm{O}$ Cacaulista, publicado em Santos, ao mesmo tempo lança Cenas da vida do Amazonas: história de um pescador. Nos dois utiliza o pseudônimo de Luiz Dolzani, sendo Dolzani o sobrenome da avó paterna com raízes italianas.

Foi engajado na política pelo
Partido Liberal, fundou o Diário de Santos e a Tribuna (também pleiteou jornalismo, após Direito). Foi secretário da Relação, em São Paulo, seguidamente deputado da Assembleia Provincial. E, em especial, projetou a criação da Escola Normal. Chegando a ser presidente da Assembleia do Estado de Espírito Santo, mas fracassou. E, em 1883, retorna à profissão de advogado, por questão de saúde. Em 1888 lança $O$ Missionário. Posteriormente recebe vários títulos, dentre eles: Fundador da Academia Brasileira de Letras (1896), tendo como patrono Manuel Antônio de Almeida, sendo ocupante da cadeira vinte e oito; Diretor da Faculdade de Ciências Jurídicas e Sociais; Presidente do Instituto da Ordem dos Advogados; Presidente da Comissão para a unificação da legislação sobre letras de câmbio, no Congresso Financeiro Pan-Americano (Buenos Aires). Debilitado, faleceu em 6 de Setembro de 1918, aos 65 anos.

O estudioso e professor Paulo Nunes, doutor em Literatura Comparada resenha sobre o contista, no artigo Inglês de Sousa: dois dedos de prosa sobre a recepção da obra, na revista Asas da Palavra (2003), da Universidade da Amazônia:

Se folhearmos os manuais
de Literatura Brasileira do
nível médio de ensino, nos
depararemos com uma
injustiça não muito rara:
qual o iniciador do
Naturalismo no Brasil?
Aluísio de Azevedo, certo?
Certo! É o que dirão os
livros escolares. Errado! É
o que dirá, de certa forma,
nossa consciência
xndignada. Nada contra
Aluísio de Azevedo (para
mim O Cortiço é uma
obra-prima do romance de


tese! O leitor que não leu este romance apresenta, sem dúvida, uma lacuna em seu repertório). Mas a indignação se deve ao silêncio ou ao desprezo que se abate sobre os escritores do Norte do Brasil. $O$ que impediu a crítica e a historiografia brasileira de reconhecer no autor de $\mathrm{O}$ Coronel Sangrado o iniciador do nosso Naturalismo? (NUNES, 2003, p.1).

Inglês de Sousa, segundo Nunes (2003), deveria ser reconhecido como o iniciador do Naturalismo brasileiro. Fato confirmado por Lúcia Miguel-Pereira, com a obra Prosa e Ficção, afirmando que a obra $O$ Coronel Sangrado (1877) foi publicada quatro anos antes de $O$ Mulato (1881), de Aluísio de Azevedo. Em Sousa (1991), Antônio Oliveira revela em o prefácio da obra 0 Missionário, obra datada de 1982:

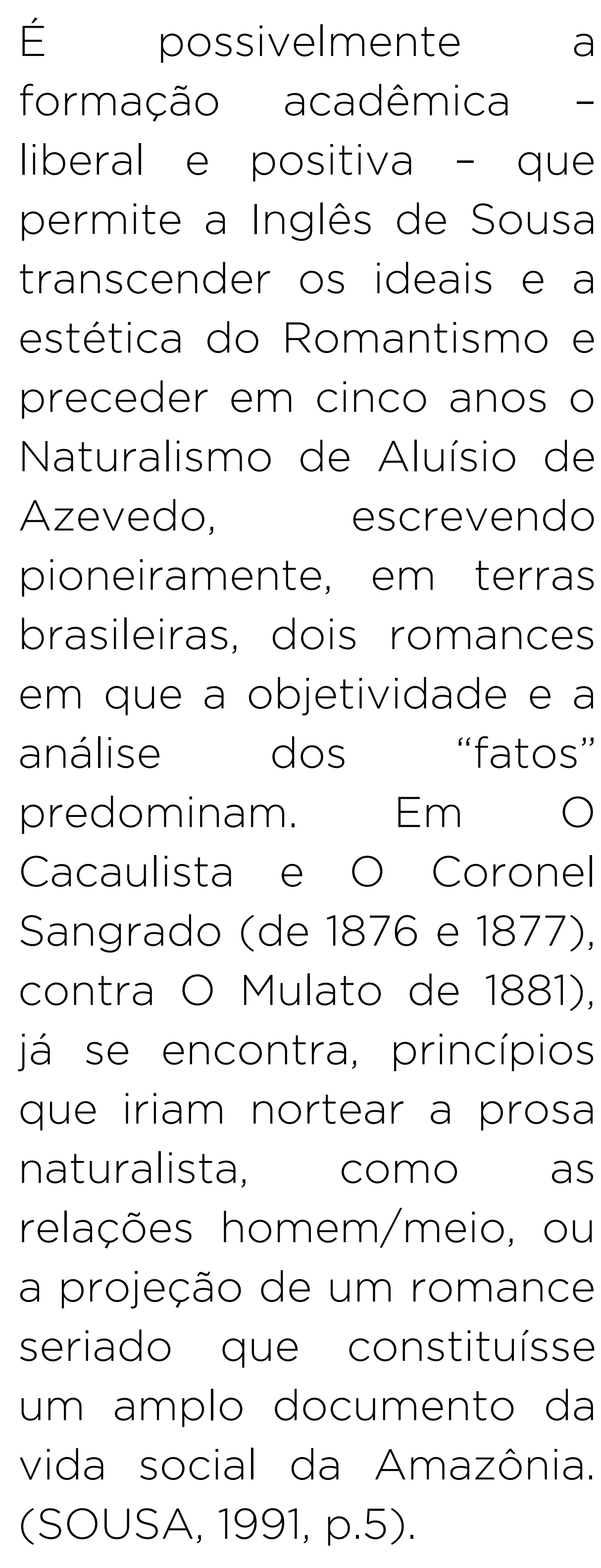

As características da estética Realista/naturalista são as marcas das narrativas de Inglês de Sousa, descrevendo o cotidiano social, as mazelas regionais, as práticas culturais regionais e a relação do homem com seu meio, porém não podemos negar a presença do lirismo e do fantástico que são demonstrados em Contos Amazônicos (1978), como em "Acauã", "A feiticeira", "O baile do judeu", "O gado do Valhame-Deus e "Amor de Maria", todos possuem a presença de um fenômeno que não pode ser explicado pela racionalidade. Fenômenos sobrenaturais, reconhecidos nos textos de Inglês de Souza, representados na tessitura de sua narrativa que mesmo na contra-mão da escola Naturalista, justifica-se pela vivencia, legitimação e crença do Amazônida Zola (1982), em seu livro $O$ Romance Experimental (1982) afirma:

$$
\begin{aligned}
& \text { Nós, os escritores } \\
& \text { naturalistas, submetemos } \\
& \text { cada fato à observação e } \\
& \text { à experiência; enquanto } \\
& \text { que os escritores ideali- } \\
& \text { stas admitem influências } \\
& \text { misteriosas que escapam } \\
& \text { à análise, e permanecem } \\
& \text { por isso no desconhecido, } \\
& \text { fora das leis da natureza. } \\
& \text { Esta questão do ideal, } \\
& \text { cientificamente, reduz-se } \\
& \text { à questão do } \\
& \text { indeterminado e do } \\
& \text { determinado. Tudo o que } \\
& \text { não sabemos, tudo o que } \\
& \text { nos escapa ainda, é o } \\
& \text { ideal; e o alvo de nosso } \\
& \text { esforço humano é reduzir } \\
& \text { dia a dia o ideal, con- } \\
& \text { quistar a verdade ao } \\
& \text { desconhecido. Somos } \\
& \text { todos idealistas, se se } \\
& \text { entende com isso que } \\
& \text { nos ocupamos com o } \\
& \text { ideal. Mas, chamo } \\
& \text { idealistas àqueles que se } \\
& \text { refugiam no } \\
& \text { desconhecido pelo prazer } \\
& \text { de nele estar. (ZOLA, } \\
& \text { 1982, p.6o-61). }
\end{aligned}
$$

Inglês de Sousa demonstra que o realismo pode caminhar com a presença do fantástico, pois os fenômenos são elementos muito presentes no cotidiano social amazônico. Ou seja, o mistério dos mitos, o folclore e lendas urbanas permeiam as narrativas deste autor. Após as críticas literárias a respeito de suas obras, ficam claras as tendências estéticas das narrativas do autor, importantes para compreender a parte a seguir.

\section{POSSÍVEIS DIÁLOGOS ENTRE HISTÓRIA, LITERATURA E O CONTO O REBELDE, DE INGLÊS DE SOUSA}

No conto $\bigcirc$ Rebelde, presente na obra Contos Amazônicos (2005), o personagem Luís, conta sua experiência de convívio com Paulo da Rocha, descrito como um velho veterano da Revolução Pernambucana de 1817, também habitante da Vila Bela.

A narrativa traz a história do personagem Luís, ainda criança. Mostra a amizade entre Luís, Julia e Paulo da Rocha, um homem desprezado por toda a população de Vila Bela, por ter participado da revolta de 1817 , em Pernambuco. Com a Cabanagem o clima fica tenso em Vila Bela. Os cabanos invadem o lugarejo, matam Guilherme da Silveira, pai de Luís, português e juiz de paz do local. Paulo salva o filho e a esposa do juiz, fugindo juntamente com o padre e Julia para o sítio da velha Andresa. $O$ texto segue contando as várias situações vivenciadas pelos personagens no sítio. Paulo mostra-se um grande amigo e protetor dos refugiados. Como último problema, Paulo tem sua filha capturada pelos revoltosos, que propõem uma troca de Julia pelo filho do juiz, e mais uma vez Luís é salvo, pois Paulo não faz a troca. 
O conto termina com Luís adulto, reencontrando Paulo que havia sido preso. Luís consegue a liberdade de seu amigo, mas Paulo morre em seguida.

A história se passa no povoado de Vila Bela, nos tempos de Cabanagem. Destaca a mudança no comportamento da população, bem como a situação de pânico vivida pelos moradores, e as tentativas para solucionar os problemas da Vila, realizadas pelas pessoas mais gradas do local, como por exemplo, o tenente coronel e o juiz, que se reuniam para pensar em meios de resistência aos cabanos. $\bigcirc$ primeiro aspecto que merece atenção é o próprio título do conto $\bigcirc$ Rebelde, pois quando lemos esse título nos perguntamos: Quem é o rebelde? Por que é rebelde? Essas perguntas têm suas respostas ao longo do texto. A primeira resposta para essas perguntas é que Paulo da Rocha é o rebelde, pois participou da revolta de Pernambuco e, é visto pela sociedade de Vila Bela como um velho rebelde. Depois é possível também entender que o narrador, o personagem de Luís, é o rebelde, pois o garoto mostra-se possuidor de um espírito rebelde, como se verifica no trecho abaixo:

Desde a mais tenra infância, vivi sempre em contradição

de sentimentos e de idéias com os que me cercavam: gostava do que os outros não queriam, e tal era a predisposição malsã do meu espírito rebelde e refratário a toda a disciplina que $\mathrm{o}$ melhor título de um homem ou de um animal à minha afeição era ser desprezado por todos (SOUSA, 2005, p.131).
Luís e Paulo têm um espírito rebelde: a grande marca dos personagens. Mas O personagem de grande destaque se materializa em Paulo da Rocha, que aparece como uma voz de experiência (ele é um homem velho); ele representa o conhecimento (tinha o hábito de ler) e a rebeldia (participou da revolta em Pernambuco, e apoia de certa forma a luta dos cabanos); é também o velho do outro mundo (figura lendária para os garotos) e um presságio funesto para o pai de Luís (quando aparece na porta da casa antes da invasão dos cabanos). Mas acima de tudo, Paulo da Rocha é um grande herói, um homem honesto, simples, que tem consciência de sua situação social e que é capaz de renunciar muitas coisas para salvar um grupo de amigos.

A narrativa traz duas visões sobre o movimento cabano: uma que condena a revolta, visão dos brancos, portugueses, pessoas que detinham o poder; e outra que mostra ser justa a luta dos cabanos, visão defendida pelos grupos excluídos. A visão que condena o movimento cabano está presente em alguns momentos, como por exemplo quando se apresentam as práticas cruéis realizadas pelos cabanos, como no trecho a seguir. Paulo da Rocha se coloca como defensor dos cabanos:

Bater os cabanos! Uns pobres diabos que a miséria levou à rebelião! Uns pobres homens cansados de viver sobre - despotismo duro e cruel de uma raça desapiedada! Uns desgraçados que não sabem ler e que não tem pão... e cuja culpa é só terem sido despojados de todos os bens e de todos os direitos [...] e quem disse ao senhor padre João que eu, Paulo da Rocha, o desprezado de todos em Vila Bela, seria capaz de pegar em armas contra os cabanos? [...] Diziam de homens queimados vivos, de mulheres violadas e esfoladas e do terríve correio, suplício que inventara a feroz imaginação de um chefe. Consistia em amarrar solidamente os pés e as mãos da vítima e embarcála assim em uma canoa que, entregue à correnteza do rio, abria água com poucos minutos de viagem" (SOUSA, 2005 p.144 148)

Embora Paulo da Rocha seja defensor da causa dos cabanos, não concorda com a violência praticada pelos revoltosos, como entendido no excerto:

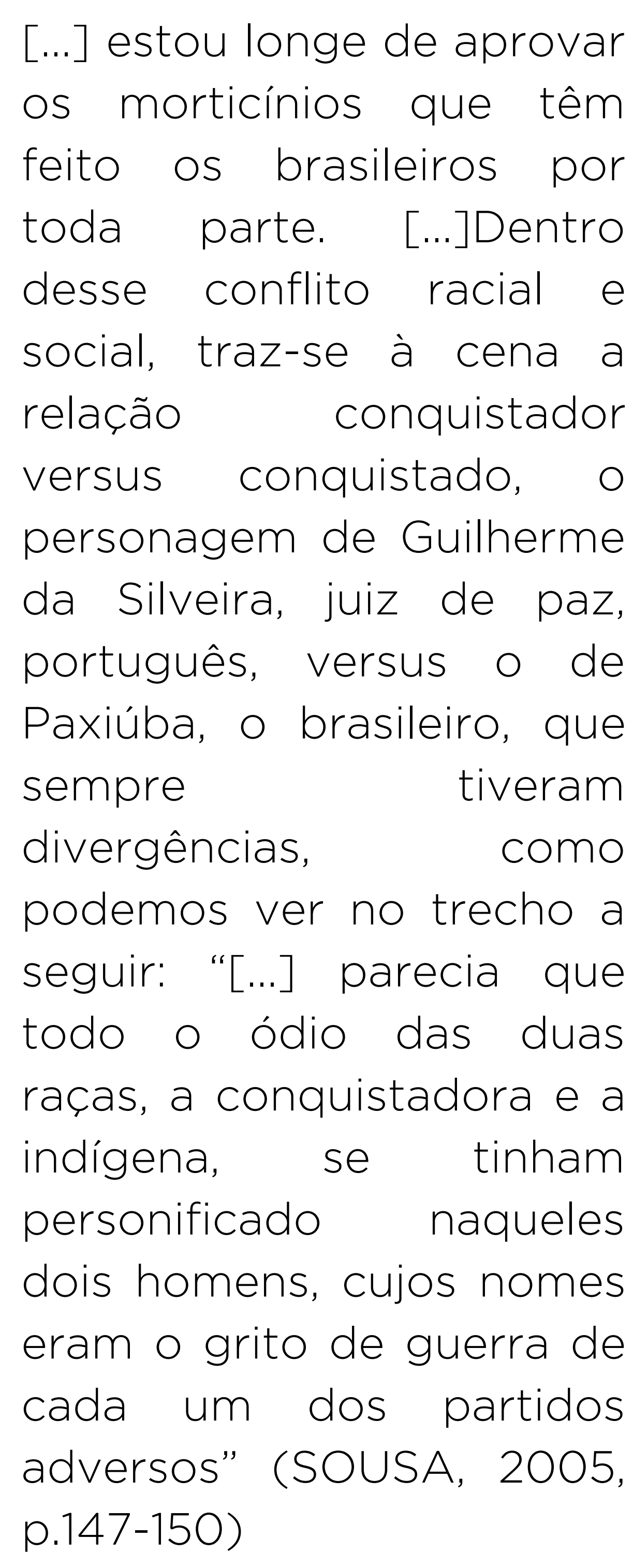

Esses dois personagens representam bem a luta entre o conquistador, representando a civilização e o conquistado representando a ignorância, a superstição, o fanatismo. 0 texto também revela a 
crueldade dos guardas, que fazem um cerco ao grupo de Matias Paxiúba, matam homens, mulheres e crianças. Os guardas também acham natural todas as brutalidades cometidas contra "os revoltosos" e só lamentam ter conseguido um único prisioneiro. Como é percebido na fala do tenente-coronel Miranda:

Atirando-se à água. Muitos deles foram mortos a tiro, outros se afogaram, alguns foram comidos de jacarés. Quando descobri a fuga mandei ativar o fogo Ardeu das palhoças. [...] Os que não se atiraram à água foram poucos. Mulheres e crianças morreram queimadas. Era natural. Nós não lhes podíamos acudir. O que é lamentável é que só se fizesse um prisioneiro, mas esse era de muita importância (SOUSA 2005, p.196)

ILendo o conto "ganhamos" possibilidades de visão de acontecimentos entre portugueses e cabanos. E como afirma Cunha (1991), a literatura em questão nos simboliza um caminho "(com pistas) para revelar um lugar, um tempo e uma situação histórica. A história limitada ao questionamento do real às vezes tende a "esconder" trechos de fatos, dito que os próprios fatos são manipulados por um olhar. A literatura tem ampliado este campo de olhar, visto que seu discurso alega uma liberdade de expressão e intimismo daquele que escreve e este também é defendido pelo discurso do material "ficcional" da obra de arte com palavras.

Além de tudo, este trabalho promove o conhecimento histórico, afim de divulgar a história da Cabanagem e provocar cientificamente os estudiosos da área de Letras a buscar à fundo as histórias que pairam sobre o "mundo" dos escritores, em especial os paraenses.

\section{CONSIDERAÇÕES \\ FINAIS}

Reconstruir a história com apropriação e legitimidade da Literatura, resume o objetivo desse artigo. Buscar uma narrativa que desse conta de estabelecer pontes entre a memória histórica e a narrativa ficcional de um dos mais influentes escritores amazônicos, foi o fio condutor que sedimentou os caminhos percorridos nessa análise. Na intersecção da relação de produção da escrita literária com a construção histórica, descobrimos na obra $\bigcirc$ Rebelde de Inglês de Sousa, um envolvimento próprio a sua construção estética. Relacionado expressivamente com o cotidiano que o cerca, as relações de poder, a vivência, os diálogos e as refutações de uma região que inspirou o seu fazer literário.

Na história apontada por historiadores e no conto de Inglês de Sousa, percebemos que a história da Cabanagem é dividida entre diferentes visões. Demonstrando que o autor reconstrói o teor histórico perpassando pelo literário e propicia uma reflexão do homem cabano idealizado ora como vilão, inserido em uma visão do movimento ligado a revolta em si, e a prática cruel dos revoltados, ora como destaque de uma das maiores revoluções amazônicas, com ideais de profundas mudanças sociais.

Reconfigurar um ambiente vivente por esse homem amazônico, torna a obra de Inglês de Souza singular e estabelece uma relação na interface interdisciplinar da história e da Literatura. Falar sobre Literatura implica em reconstruir História, Cultura e Memória. E que não importa a definição concreta que é vislumbrada cientificamente do que venha ser Literatura ou História, o essencial é estabelecer relações, discursos e redescobrir textos, em cada leitura e pesquisa. Como saber quem eram os rebeldes, pelo próprio autor, seria tirar parte significativa do mistério narrativo vislumbrando possibilidades de entendimento do fantástico mundo Amazônico. Inglês de Souza se apropria do sentimento de pertença e do conhecimento que possui das singularidades dessas terras e tão bem estabelece em seu fazer poético a relação do Amazônida com a terra, com os rios e com o ar, que legitima as crenças e tradições, cristaliza o fantástico e o sobrenatural, dentro de uma estética positivista, determinista. 


\section{NOTAS}

[1] Jacques Derrida (1930-2004) foi um grande filósofo franco-argelino que elaborou a chamada Teoria da Desconstrução, em 1960. Sua teoria leva como princípio maior a inexistência da verdade absoluta. E, de acordo com seu método de pensar a realidade e a linguagem, os textos são decompostos de tal maneira que não é possível uma só interpretação verdadeira. Para maior conhecimento a respeito de sua vida e sua obra é recomendável a leitura do livro Derrida, do francês Benoit Peteers.

[2] Ernesto Cruz foi um historiador paraense (1898-1976), natural de Belém, participante da Revolução de 30. Personalidade que publicou cerca de 21 livros, entre eles: "Noções de História do Pará", "Nos bastidores da Cabanagem", "Ruas de Belém" e "Monumentos de Belém". Recebeu da Câmara Municipal de Belém, o título de Historiador da Cidade. Foi membro da Academia Paraense de Letras e do Instituto Histórico e Geográfico do Pará. Para maiores informações.

\section{REFERÊNCIAS}

CHARTIER, Roger. A história ou a leitura do tempo. Belo Horizonte: Autêntica, 2009.

CHIAVENTAO, José. Cabanagem: o povo no poder. São Paulo: Brasiliense, 1984

CUNHA, José Carlos Chaves da. Pragmática lingüística e didática das línguas. Belém: Universidade Federal do Pará, 1991.

DELIZOICOV, Demétrio; ZANETIC, João. A proposta de interdisciplinaridade e seu impacto no ensino municipal de $1^{\circ}$ grau. In: PONTUSCHKA, Nídia N. (Org.) Ousadia no diálogo: interdisciplinaridade na escola pública. São Paulo: Loyola, 2001.

EAGLETON, Terry. Teoria da Literatura: Uma Introdução. São Paulo: Martins Fontes, 1997.
FREITAS, Dionne Seabra. Fantástico e Imaginário em Contos de Inglês de Sousa. 2013. Dissertação (Mestrado em Letras). Programa de PósGraduação em Letras, Universidade Federal do Pará, Belém, 2013

LIMA, Luiz Costa. Sociedade e Discurso ficcional. Rio de Janeiro: Guanabara, 1986.

NUNES, Paulo. Inglês de Sousa: dois dedos de prosa sobre a recepcão da obra. Asas da Palavra. 8(1), 2003.

$\mathrm{RICCl}$

Magda. Do sentido aos significados da Cabanagem: percursos Historiográficos. In. Anais do Arquivo Público do Pará, 2001, Belém-PA. Anais... Belém: 2001.

SARGES, Maria de Nazaré; RICCl, Magda Maria de Oliveira (Org.). Os oitocentos na Amazônia: política, trabalho e cultura. Belém: Açaí, 2013.

ROCQUE, Carlos. Cabanagem: epopeia de um povo. Belém: Imprensa Oficial, 1984

SOUSA, Inglês de. Contos amazônicos. São Paulo: Martins

Fontes, 2005. O Missionário. São Paulo: Ática, 1991.

ZOLA, Emile. O Romance Experimental. São Paulo: Perspectiva, 1982.

\section{Artigo recebido em: 02 Dez 2019. I Artigo aprovado em: 21 Maio 2020}

[i] Mestre em Linguagens e Saberes Interculturais na Amazônia, pelo Programa de Pós-graduação em Linguagens e Saberes na Amazônia (PPLSA) da Universidades Federal do Pará (UFPA). É vinculada ao Grupo de Pesquisa COLINS (Colaboratório de Interculturalidades, Inclusão de Saberes e Inovação Social). Professora e pesquisadora com foco nas áreas de Teoria Literária; Literatura, Memória e Saberes; Literatura e Estudos Culturais.

Orcid: http://orcid.org/0000-0002-9634-3969

E-mail: letras.laura@gmail.com 